\title{
AULA MAGNA DO PROFESSOR TITULAR JOSÉ IGNÁCIO BOTELHO DE MESQUITA
}

\begin{abstract}
O Professor Titular de Direito Processual, José Ignácio Botelho de Mesquita, ministrou no dia $I^{\circ}$ de junho p.p.. aula especial, no Salão Nobre da Academia de Direito, na qual se despediu da função de professor por ter-se aposentado.

Lecionando desde 1964, regendo a disciplina que, na época, se chamava Dircito Judiciário Civil, para o curso de formação do terceiro ano, período inclusive que sobreveio o golpe militar, o Professor Botelho de Mesquita cumpriu brilhantemente sua carreira como um dos maiores mestres desta Escola, sempre a defendendo quanto a sua autonomia didática e cientifica.

No término de sua última aula, utilizou-se de versos de Martins l:ontes, e a encerrou, expressando-se: "é chegada enfim a minha hora" comovendo a platéia lotada que veio prestigiá-lo.
\end{abstract}

A Redação

José Inácio Botelho de Mesquita

Aula $\left(1^{\circ}\right.$ de junho de 2005$)$

1. Esta aula teve o scu começo numa clara manhã de abril de 1964. Já estamos no outono de 2005 c eu ainda a estou a dar. Nesta noite. outonal por todos os títulos, termino eu de dá-la, mas não termina ela de ser dada. Saio eu. A Faculdade fica.

Para entender esta aula, é preciso entender a sua história. É preciso conhecer o seu começo.

Em novembro de 1963, incentivado por Luiz Eulálio de Bueno Vidigal, prestei meu concurso à livre-docência e, já para o ano letivo de 1964, fui por ele incumbido da regência da disciplina, que então anda se chamava Direito Judiciário Civil, para o curso do terceiro ano diurno.

Em meados de março, começaram as aulas. Carregado de emoção, tive meu primeiro contato com a classe. A recepção que tive, absolutamente surpreendente, totalmente inesperada para quem nunca havida dado um dia de aula sequer nesta ou em qualquer outra Faculdade, aquela recepção sagrou-me, naquele dia e para o resto da minha vida, professor desta casa, da Faculdade de Direito de São Paulo. Os alunos de então, hoje respeitabilíssimos senhores e senhoras na casa dos sessenta anos. os alunos sim, bem mais

Professor Titular de Direito Processual Civil da Faculdade de Dircito da I nniversidade de São Paulo. 
do que o concurso precoce, ungiram-me com esta dignidade e me investiram do ônus a ela inerentes.

Apenas iniciadas as aulas, sobrcveio o golpe militar de 1964. Suspenderamse as aulas por alguns dias e, numa segunda-feira, ainda no mês de abril, reabriu-se a Faculdade. Se não me falha a memória, a minha aula era a primeira do dia. E a comecei dizendo: "Meus senhores, terminou o processo militar. Vamos retomar o processo civir"

Com estas palavras, eu não sabia mas não tardaria a vir a sabê-lo, eu acabava de empenhar o meu destino na perseguição de uma causa. Eu acabava de empunhar uma bandeira e de fincá-la no estrado de minha sala de aula, ao lado de minha mesa de professor, no estrado de todas as minhas salas de aula e de todas as minhas mesas de professor, como se a houvera fincado no centro do nosso pátio, no coração mesmo das nossas venerandas Arcadas. Motivo talvez para nunca me haver proposto lecionar em outras escolas.

Não era uma bandeira qualquer. Vim sabê-lo depois. No seu tecido entrelaçavam-se panos ásperos de duras mortalhas, véus diáfanos de miríades de versos. grilhões rompidos de tenebrosos calabouços, o verbo incandescente daqueles para quem a vida reservou o encargo inexaurivel de opor, à tirania, a lei.

Com aquelas palavras, eu não sabia, eu acabava de empenhar o meu destino na defesa de uma causa: a da luta pelo processo civil e contra o processo militar.

Em termos mais simples afinal, pode-se perguntar, o que significa tudo isto? Eu vou explicar.

2. O processo civil e os processos militares têm algo em comum: põem em confronto a força do Estado e a força do povo, a força material do Estado e a força imaterial do povo. As coincidências param aí.

As diferenças são muitas, mas podem ser sintetizadas no modo como atuam o processo civil e o processo não civil em relação à lei.

Ao processo militar a lei não importa, importa a disciplina; no mais das vezes, a lei é um estorvo a ser posto de lado enquanto os objetivos não são totalmente realizados, vencidas todas as resistências. Se a lei foi cumprida, ou não, é indiferente.

Ao processo civil, ao contrário, a lei é tudo o que importa. Estorvo é tudo o que impeça o conhecimento exato do direito e o cumprimento exato da lei, único instrumento de defesa no confronto da sociedade civil com a potestade estatal, de defesa, antes de mais nada, da liberdade política do povo.

Dela advém, disse Montesquieu, a exigência de que os julgamentos "nunca sejam mais do que um texto exato da lei" porque "se fossem a opinião particular do juiz, viver-se-ia na sociedade sem saber precisamente os compromissos que nela são 
assumidos" No mesmo sentido, advertia Locke, consistir a liberdade "em não estar sujeito de modo algum à vontade inconstante, incerta, desconhecida, arbitrária, de um homem" Aí se traça a linha divisória entre a liberdade e a tirania. Relembrem-se, as palavras de Antígone, ressoando das profundezas dos séculos: "Esta é a vantagem dos tiranos: dizer e fazer tudo o que entendem" O tirano é sempre a legibus solutus.

Daí haver sublinhado, ainda no século XIX, Francisco de Paula Baptista, ter o processo civil "diversos periodos, que constituem a sua ordem natural, lógica $e$ imutável, de tal sorte que não pode ser destruida ou ofendida, sem que se viole a justiça, $e$ apareça a deserdem ou tirania"

Processo civil é isto. Nisto se condensa a alma do processo. Processo incivil é o seu oposto; é processo do qual nunca se sabe qual será o resultado, nunca se sabe se se conduziu com justiça. porque predisposto a ocultar. a camuflar, a impedir que apareça a desordem ou tirania.

3. Sabedores disto, deram os militares, assim que assumiram o poder, deram os militares início à destruição do processo civil. De pronto, suprimiram as garantias de vitaliciedade e estabilidade dos juizes, transformando-os, para usar um expressão empregada por Piero Calamandrei, em "strumentun regni" No ano seguinte, ainda não satisfeitos, subtraíram ao conhecimento do Poder Judiciário, pelo Ato Institucional n. 2, "os atos praticudos pelo Comundo Supremo da Revolução, com fundamento no Ato Institucional de 9 de abril de 1964, no presente Ato Institucional e nos complementares deste" Não satisfeitos ainda, foram mais adiante. Pela Emenda Constitucional n. 7 de abril de 1977, submeteram os juizes brasileiros a uma hierarquia militar tendo como cúpula o Conselho Nacional da Magistratura, composto por ministros do Supremo Tribunal Federal (algo que se está reproduzindo hoje sub specie do Conselho Nacional de Justiça); conferiram ao Supremo 'Tribunal Federal o poder de avocação de causas, em detrimento do princípio do juiz. natural (o que também reaparece hoje na argüição de descumprimento de preceito fundamental), e impuseram ao Supremo o rebaixamento maior: o dever de responder consultas prévias do procurador geral da República, sobre como seria interpretada alguma lei caso esta interpretação tivesse que ser discutida em algum caso concreto: a chamada interpretação em abstrato, costume que a Inglaterra, trezentos anos antes já repudiara. O que também ressurge na atualidade, sob a forma da "interpretação conforme" nas ações de declaração de constitucionalidade.

Foi uste o começo da destruição imposta ao processo civil brasileiro para a sobrevivência dos ideais que inspiram o processo militar. Foi só o começo. Golpe mais profundo foi vibrado em 1984, já agora por mãos não militares, mas francamente autoritárias, herdeiras do império já então em franca derrocada. 
4. Criaram-se em 1984, com grande alarde, como é próprio das instituições totalitárias, os Juizados de Pequenas Causas, cujo projeto ocultava objetivos incontessáveis.

Do projeto submetido à discussão das entidades representativas da sociedade civil, as Universidades inclusive, constava: "Art. 5" - O juiz decidirá com base na lei, atendendo aos seus fins sociais, às exigências do bem comum, adotando em cada caso a solução que reputar mais justa e equânime" Um pastiche aparentemente inocente, que chamava a atenção pelo aberto contraste com a norma do art. 57 do mesmo projeto, que dizia: "Não se admitirá ação réscisória nas causas sujeitas ao procedimento instituido nesta lei" Ou seja, deveria o juiz decidir com base na lei mas, se decidisse contra a lei, prevaleceria sua decisão do mesmo modo.

A incompatibilidade se desfez no texto da lei que acabou sendo aprovada. Cortando a exclusão da ação rescisória? Não: cortando a expressão "com base na lei" A norma ficou assim: "() juiz udotará em cada caso a decisão que reputar muis justu utendendo aos fins sociais da lei è às exigências do bern comum" Ficou dispensado o juiz de decidir com base na lei, o que guarda conformidade com a exclusão da ação rescisória por of ensa a disposição literal da lei, mas é incompatível com a Constituição Federal.

Estava criado, enfim, um processo onde não vigoraria, o princípio da legalidade, segundo o qual ninguém pode ser obrigado a fazer ou deixar de fazer alguma coisa senão em virtude de lei. Pior do que isto, a escolha entre a ida ao Juizado de Pequenas Causas ou à Justiça Comum, onde mal ou bem ainda impera o princípio da legalidade, ficou relegada à opção do autor; e assim continua a ser hoje em dia a despeito da alteração da lei, quando foram substituídos os Juizados de Pequenas Causas pelos Juizados Especiais Cíveis e Criminais.

Estejam certos, meus senhores, mercê desta inovação, é o Brasil o único país do mundo $\mathrm{em}$ que cabe a uma das partes do litigio a escolha da lei pcla qual a outra parte será julgada.

Isto, porém ainda estava longe de satisfazer o apetite tirânico e as inclinações despóticas, que informam o ideário do processo autoritário, incivil. Era apenas um balão de ensaio para experimentos mais contundentes.

5. abafadas as vozes discordantes, inaugura-se em 1993 a era das minireformas do Código de Processo Civil. O seu carro-chefe viria por uma lei de 1994. A Lei n. 8.953. A pretexto de agilizar o processo, de resgatá-lo da incurável demora que a ele nunca se deveu, mas, sim, à permanente falta de recursos para operá-lo, quebrou-se a coluna vertebral do sistema. 
Pela introdução da antecipação da tutela, partiu-se em dois a estrutura do processo conhecimento, invertendo-se os termos da garantia constitucional do devido processo legal. A regra de que "ninguém será privado de sua liberdade ou de seus bens sem o devido processo legal". foi substituida pela de que "qualquer um pode ser privado de sua liberdade ou de seus bens sem o devido processo legal; beneficio este que, após consumada a privação, Ihe será integralmente concedido para que se queixe à vontade"

Trasladou-se dos Juizados de Pequenas Causas para a Justiça Comum a desnecessidade de uma sujeição real e efetiva do resultado do processo ao império da lei. $\mathrm{Na}$ sua primeira fase, perante o juiz singular ou tribunal, satisfaz-se o processo com um juizo de verossimilhança, como na comédia de Pirandello. Cosi é si vi pare: Assim é se Ihe parece. Na segunda fase há ainda, em tese, alguma probabilidade, escassa é bem verdade, de fazer reverter a decisão. Menos, bem menos provável, a de reverter a situação de fato criada pela antecipação da tutela.

Ciente deste risco, a despcito de remotíssimo, aprestou-se a vocação autoritária a ir à busca da consolidação das sentenças de primeiro grau, enfraquecendo o quanto possível, e cada vez mais, o controle pelos tribunais da conformidade de sentença com a lei. Sirva de exemplo a supressão do efeito suspensivo da apelação contra sentença que confirma a antecipação de tutela. É. este apenas um exemplo. Muitos outros podem ser lembrados.

6. Mediante novas alterações do Código de Processo Civil, passaram os recursos a poder ser decididos, em boa parte. não mais por um órgão colegiado, mas por um segundo juiz singular. o Relator, perdendo o Tribunal a sua feição constitucional. Cada Relator, por sua vez, passou a poder dispor oficialmente de um ou mais assessores, que nem juizes precisam ser e são escolhidos pelo Desembargador ou Ministro "ad libitum", a despeito de pagos pelo erário.

Não pára aí a descaracterização, o desfiguramento, dos Tribunais. Surgem no Tribunal de Justiça as novas "Câmaras A" constituídas só por juizes de primeiro grau com funções de desembargadores, posto a que não foram alçados por nenhum critério legal. São chamados de substitutos em segundo grau. que a ninguém substituem, o que é expressamente proibido pelo art. 107 da Lei Orgânica da Magistratura Nacional.

Isto, porém, ainda não é tudo. Para limpar o estoque de processos inventaram-se "mutirões" nos quais as causas não são julgadas pelos juizes naturais, mas por outros quaisquer que se interessem por perceber o chamado "auxilio sentença", obrigando-se a receber quarenta processos para serem decididos em trinta dias, rompido acintosamente o princípio do jui $z$ natural.

Assiste-se hoje, promovida abertamente, a terceirização da Justiça. 
O resultado de tudo isto, como não poderia deixar de ser, são decisões destituídas de autoridade, com as quais os vencidos não podem, nem devem, se conformar; o que geral mais recursos e maior oposição à execução das sentenças. $O$ arsenal do processo incivil é vasto, porém. Soluções tirânicas há para tudo e já estão sendo introduzidas na lei.

7. Para suprir a faita de autoridade das decisões judiciais foi introduzido no Código de Processo Civil um sistema punitivo que se alastra cada vez mais, indo das mais diversas sanções pecuniárias até a prisão civil, nada importando o quanto isto seja proibido pela Constituição da República. Há o escopo inocultável de silenciar os advogados, inclusive os que nunca se afastaram do exato cumprimento dos deveres que a ética lhes impões, numa tentativa aberta de criminalização da advocacia. Institucionalizase uma nova forma de Terror: o terrorismo judicial.

A serviço desse novo Terror, inventou-se até um nodo delito, uma nova hipótese de punibilidade: o descumprimento pela parte de provimentos mandamentais. Quem quer que se dê ao trabalho de empenhar-se verdadeiramente no estudo das sentenças mandamentais verá que a hipótese de descumprimento das sentenças mandamentais por ato da parte é uma contradictio in terminis. Ou a sentença comporta descumprimento pela parte e, neste caso, não é mandamental; ou a sentença é mandamental e não é suscetível de descumprimento pela parte.

Por outro lado, para diminuir a resistência à execução das sentenças está sendo paulatinamente minado o direito de defesa do devedor. Muito já se fez nesta senda e mais está por fazer-se, com a eliminação dos embargos à execução.

A pouca resistência à abertura dessas fendas no sistema processual tem sido um incentivo a que outras se abram, mas audazes, como a da estabilização do resultado das tutelas antecipadas e a desestabilização da coisa julgada, esta sim uma verdadeira pá de cal no processo civil.

8. Em suma: o processo civil está sendo metodicamente destruído; o processo incivil progride; o império da lei claudica.

Lutei contra isto. Todos aqui sabem da minha luta. Travei-a por mais de quarenta anos, principalmente no estudo e na docência do Direito Processual Civil. Documentei-a em alguns escritos: Da ação civil, de 1973, O principio da liberdade na prestação jurisdicional. de 1980, A crise do Judiciário, O desmantelamento do sistema brasileiro de controle de constitucionalidade, As novas tendências do direito processual: uma contribuição para o seu cstudo, todas de 2002, A revisão do Código de Processo Civil, de 2004, A nova execuçâo de sentença, de 2004, A coisa julgada, deste ano de 2005.

Tudo isto, porém, é muito pouco, é quase nada, mas coloca uma questão. 
Suscita uma pergunta: como foi tudo isto possível à vista do povo, em pleno regime democrático, à luz do dia, sem que um levante irreprimível se erguesse em defesa da lei, do direito e do devido processo lcgal?

A resposta, meus senhores, é dura, mas é sabida e ressabida. O que falta é conhecimento do Direito.

O conhecimento atual é tão estreito, é tão superficial, tão desalinhado, que não permite aos operadores do Direito dar-se conta de que thes está sendo subtraído o senso crítico, tornando-os presa fácil de uma propaganda enganosa, fiada exclusivamente no sucesso que tem granjcado a indevida imputação, ao processo civil, de toda a culpa pela demora no andamento das causas. Como se outro remédio não houvesse para coarctála, senão cortar, retalhar, amortalhar as instituições processuais.

O que está acontecendo comprova que a universidade não está formando os quadros necessários para defender os direitos fundamentais do homem, os direitos sem os quais não é possível a evolução do homem, a convivência entre os justos, o progresso dos homens de boa vontade.

Formar estes quadros, porém, não é impossível. Longe disto. Nem é obra de custos inacessíveis. É obra que demanda alguns passos que têm seu custo, alto sem dúvida, mas demanda muitos outros passos que não custam nada.

Permito-me assinalar alguns deles.

1. Precisamos ter humildade. Precisamos reconhecer que o Brasil é um país culturalmente pubre e que não dispõe de recursos suficientes para pagar professores de graduação e de pós-graduação. Dentre os bons professores de que dispomos, temos que escolher os que responderão pela graduação e os que responderão pela pós-graduação. Temos que escolher com base na excelência: os melhores devem ser incumbidos da graduação. Quando menor o conhecimento do aluno, tanto maior terá que ser o do seu professor. Professores titulares devem dedicar-se integralmente à graduação e à orientação, só orientação, de pós-graduandos. Da pós-graduação devem ficar incumbidos os livres-docentes. As aulas e outros trabalhos excedentes à capacidade dos titulares e livre docentes, sejam atribuídos aos doutores. $\mathrm{E}$ a cada um não se imponha trabalho que exceda à remuneração possível, atendidas as regras do mercado de trabalho. Especialmente, evite-se ao máximo o desperdício de tempo dos docentes em atividades meramente administrativas que hoje se atribuem por uma infinidade de colegiados e comissões perfeitamente dispensáveis.

2. Precisamos nos convencer de que, querendo ou não, a nossa sociedade, devastada por um consumismo avassalador, não permite que um aluno de Direito viva sem trabalhar, que disponha de tempo para estudar. Não tem. Os objetivos do ensino têm 
que tomar como premissa esta limitação. Por isto, a aula teórica tem que ser expositiva, para formar a base do conhecimento, e tem que ser crítica, para que o aluno desenvolva inteligentemente a sua aptidão de não se conformar com tudo que está escrito em letra de forma. O que ele tiver que aprender irá aprender em classe. Os exames serão sua única oportunidade de trabalhar com a matéria que lhe é transmitida. As provas têm que ser corrigidas pelo professor que ministrou a matéria, não importa o seu grau, nem sua idade. A revisão de provas, em diálogo aberto com o aluno, tem que ser regra, não exceção. É o único momento em que ao professor é dado auxiliar verdadeiramente o aluno a vencer suas limitações.

3. A Faculdade tem que defender sua autonomia didática e científica, porque, o Estado brasileiro está empenhado na destruição da Universidade. Se isto já é assim de há muito, hoje está pior.Atrelado-nos aos desígnios de quem não conhece a matéria de que somos mestres, não é apenas descrer de nossa mestria, é nos deixar escravizar por quem, da nossa matéria, nada sabe, absolutamente nada. Por exemplo. linhas de pesquisa em Direito sã algemas que só nos atrasam.

4. Para que a atividade docente prospere, a disciplina é fundamental. $O$ professor tem que ser disciplinado, tem que pôr fora a sua vaidade e submeter-se religiosamente às justas expectativas de seus aluno, que nesta Faculdade, são das mais altas do País. Por exemplo, não pode ministrar uma aula que não tenha preparado antes, por maior que tenha sido o número de vezes que a tenha dado; se não a pôde preparar, é melhor que não a dê. O que disciplina o aluno é a disciplina do professor.

5. Por último, no conflito entre seus interesses particulares e os interesses do ensino do Direito, deve o professor, sempre, dar prioridade a estes sobre aqueles.

Meus senhores, é soada enfim a minha hora. A despeito de o mar estar revolto e serem contrários muitos dos ventos, retine seco o sino que indica o fim do meu turno. É hora de entregar a mãos mais descansadas a roda do leme, o comando da navegação.

Nesta hora derradeira, seja-me permitido dizer da Faculdade de Direito o que versos disse Martins Fontes da terra de São Paulo:

\footnotetext{
"De minha terra, para minha terra

Tenho vivido. Meu amor encerra

$A$ adoração de tudo quanto $\dot{c}$ nosso.

Por ela sonho num perpétuo enlevo

$E$, incapaz de servi-la o quanto devo,

Quero ao menos amá-la quanto posso".
}

São Paulo, I de julho de 2005. 


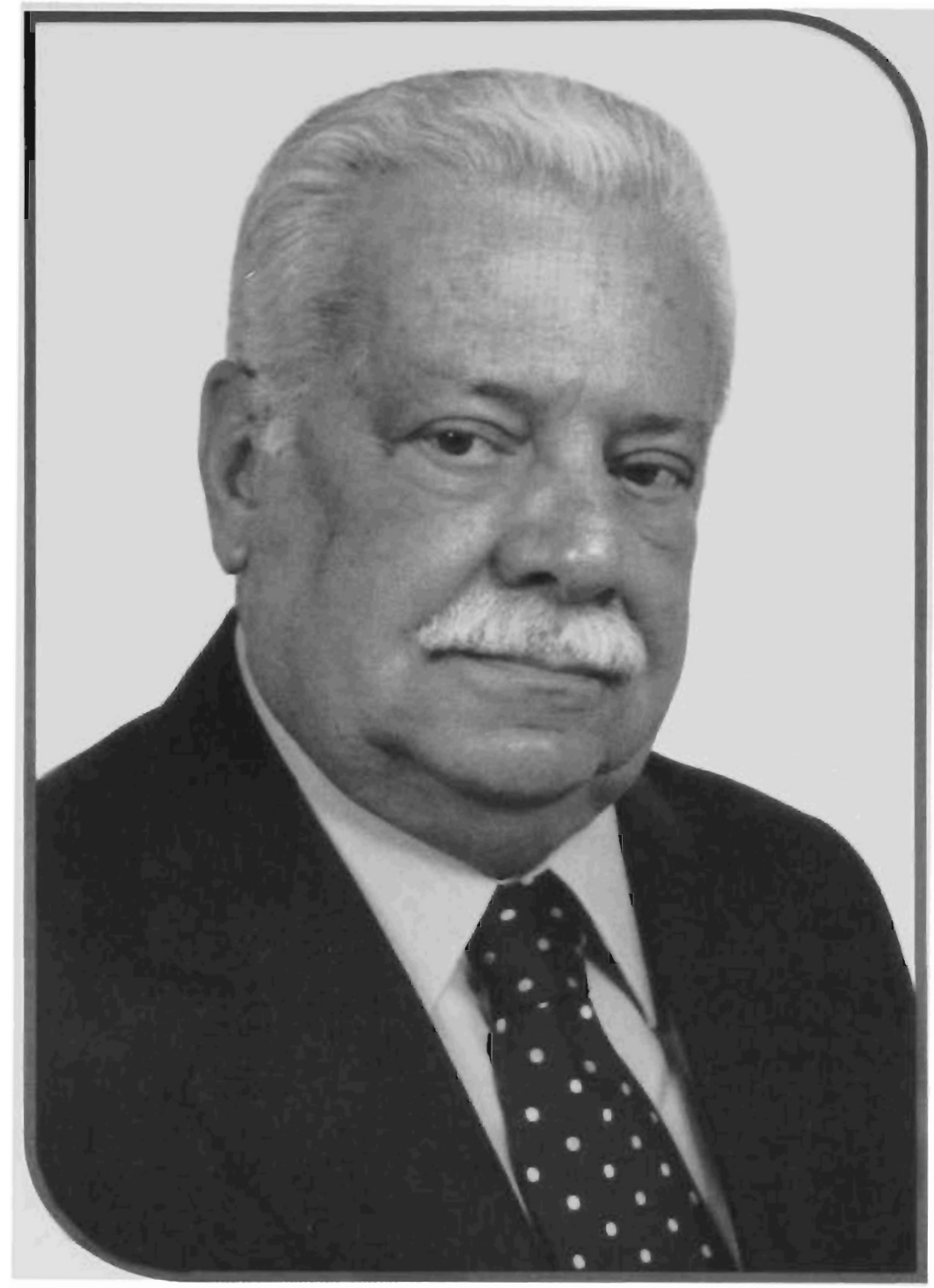

Professor Titular José Ignácio Botelho de Mesquita 